\title{
Muscle as an osteoinductive niche for local bone formation with the use of a biphasic calcium sulphate/ hydroxyapatite biomaterial
}

D. B. Raina,

A. Gupta,

M. M. Petersen,

W. Hettwer,

M. McNally,

M. Tägil,

M-H. Zheng,

A. Kumar,

L. Lidgren

Lund University,

Lund, Sweden and

Indian Institute of

Technology Kanpur,

Kanpur, India

- D. B. Raina, BA, Doctoral Student, Department of Orthopaedics,

Department of Biological Sciences and

Bioengineering,

- A. Gupta, PhD, Doctoral student,

Department of Biological Sciences and

Bioengineering,

A. Kumar, PhD, Professor,

Department of Biological Sciences

and Bioengineering, Indian Institute of

Technology Kanpur, Kanpur, 208016,

UP, India.

M. M. Petersen, MD, PhD, Professor,

Department of Orthopedic Surgery,

W. Hettwer, MD, Surgeon,

Department of Orthopedic Surgery,

Rigshospitalet, University of Copenhagen,

Copenhagen, 2100, Denmark.

- M. McNally, MD, PhD, Consultant in

Limb Reconstruction, Oxford University

Hospital, NHS Trust, Nuffield Orthopedic

Centre, Headington, Oxford, OX3

7LD, UK.

M. Tägil, MD, PhD, Professor,

Department of Orthopedics, Clinical

Sciences,

M-H. Zheng, MD, PhD, Professor, Centre for Orthopaedic Translational Research,

School of Surgery, University of Western

Australia, Crawley, Australia.

L. Lidgren, MD, PhD, Professor,

Department of Orthopedics, Clinical

Sciences, Lund University, Lund, 221

85, Sweden

Correspondence should be sent to Prof. L. Lidgren;

email: lars.lidgren@med.lu.se

doi: 10.1302/2046-3758.510.BJR2016-0133.R1

Bone Joint Res 2016;5:500-511.

Received: 12 May 2016;

Accepted: 29 July 2016

\section{Objectives}

We have observed clinical cases where bone is formed in the overlaying muscle covering surgically created bone defects treated with a hydroxyapatite/calcium sulphate biomaterial. Our objective was to investigate the osteoinductive potential of the biomaterial and to determine if growth factors secreted from local bone cells induce osteoblastic differentiation of muscle cells.

\section{Materials and Methods}

We seeded mouse skeletal muscle cells $\mathrm{C} 2 \mathrm{C} 12$ on the hydroxyapatite/calcium sulphate biomaterial and the phenotype of the cells was analysed. To mimic surgical conditions with leakage of extra cellular matrix (ECM) proteins and growth factors, we cultured rat bone cells ROS $17 / 2.8$ in a bioreactor and harvested the secreted proteins. The secretome was added to rat muscle cells L6. The phenotype of the muscle cells after treatment with the media was assessed using immunostaining and light microscopy.

\section{Results}

C2C12 cells differentiated into osteoblast-like cells expressing prominent bone markers after seeding on the biomaterial. The conditioned media of the ROS 17/2.8 contained bone morphogenetic protein-2 (BMP-2 $8.4 \mathrm{ng} / \mathrm{mg}$, standard deviation (SD) 0.8) and BMP-7 (50.6 ng/mg, SD 2.2). In vitro, this secretome induced differentiation of skeletal muscle cells L6 towards an osteogenic lineage.

\section{Conclusion}

Extra cellular matrix proteins and growth factors leaking from a bone cavity, along with a ceramic biomaterial, can synergistically enhance the process of ectopic ossification. The overlaying muscle acts as an osteoinductive niche, and provides the required cells for bone formation.

Cite this article: Bone Joint Res 2016;5:500-511.

Keywords: Biomimetic material, Hydroxyapatite, Osteopromotive, Growth factors, Osteoblast

\section{Article focus}

- Extra cellular matrix proteins and growth factors leaking from a bone cavity, along with a ceramic biomaterial, can synergistically enhance the process of ectopic ossification. The overlaying muscle acts as an osteoinductive niche, which provides the required cells to be used to transform into bone.

\section{Key messages}

- A bone defect treated with a ceramic biomaterial undergoes local remodeling but can also lead to bone formation in the muscle immediately covering the biomaterial.
- C2C12 muscle cells differentiate into bonelike cells when seeded on the biomaterial (calcium sulphate/hydroxyapatite), demonstrating the osteoinductive behaviour of the material.

- ROS 17/2.8 bone cells produce pro-osteogenic proteins BMP-2 and BMP-7, which can lead to differentiation of muscle cells.

\section{Strengths and limitations}

- This study describes a possible molecular mechanism behind ectopic bone formation when a surgically operated bone defect is treated with a biomaterial covered with a free muscle flap. 
- In future, we would perform additional studies in a larger animal model to verify our findings.

\section{Introduction}

One of the major challenges in modern orthopaedic surgery is to replace and regenerate bone. There is an increasing demand for bone substitutes that can augment and repair bone defects following trauma, infection or tumour resection. ${ }^{1}$ The ideal bone graft should be non-immunogenic, osteoinductive, osteoconductive and osteogenic. $^{2-8}$ Autologous bone fulfills these requirements but the availability is limited. ${ }^{1,4,9-12}$ Furthermore, surgery is required for its harvesting, which in turn is associated with donor site morbidity and in the worst case, infection. To overcome these drawbacks, synthetic bone grafts have been developed: mainly ceramic, polymeric or composite.1,13 Ideally, these materials should not just act as structural support but should also initiate and enhance tissue regeneration. ${ }^{12,14}$

Various studies have shown that the chemistry and surface geometry of the biomaterial in contact with mesenchymal cells play a crucial role in differentiating inducible cells from bone cells. ${ }^{15-20}$ Muscle cells such as C2C12 (murine skeletal myoblasts) have been used for studying this mechanism of differentiation. ${ }^{17,21}$ Additionally, bone matrix contains bone morphogenetic proteins (BMPs) that play an important role in the mineralisation of tissues, both ectopic and entopic. ${ }^{7,22,23}$ It is also known that muscle cells are capable of differentiating into osteogenic lineages when stimulated with signaling molecules or mineralised milieu. ${ }^{24}$

There is a clinical need for less invasive procedures with injectable materials that set in vivo, to reduce surgical invasiveness, enabling a shorter hospitalisation and quicker rehabilitation. Cerament (hydroxyapatite (HA)-calcium sulphate (CS)) (BoneSupport AB, Lund, Sweden) is an injectable composite biomaterial consisting of particles of HA and CS hemihydrates. This powder composite is mixed with a liquid solution that leads to the setting of a resorbable calcium sulphate dihydrate, embedding and binding the unreacted HA particles..$^{25}$ Recently, the first antibioticcontaining injectable bone substitute, Cerament G (HA-CS-gentamicin (G)) (BoneSupport AB), was approved for clinical use in Europe. During the initial phase of clinical testing, rapid bone regeneration was observed when the hydroxyapatite/calcium sulphate biomaterial was used to fill cavities after excision of osteomyelitis or resected bone tumours. In a few cases, bone was also found in the overlaying muscle. We hypothesise that the biomaterial can induce muscle cells to differentiate into osteoblasts at the interface between the muscle and the biomaterial. We also hypothesise that the bone induction proteins harvested from bone cell cultures could induce differentiation of muscle into bone, thereby mimicking the clinical scenario in a controlled experimental environment.
Materials and Methods

Materials. Cerament (HA-CS) and Cerament G (HA-CS-G) were supplied by Bone Support $A B$, Lund, Sweden. 3-(4.5-dimethylthiazol-2-yl)-2.5-diphenyltetrazolium bromide (MTT), Sigmafast p-Nitrophenyl phosphate (pNPP), Dulbecco's Modified Eagle's Medium - high glucose (DMEM - HG), foetal bovine serum (FBS), antibiotic cocktail (penicillin-streptomycin), TRIzol Reagent and primers for real-time polymerase chain reaction (RT-PCR) were purchased from Sigma Aldrich (St. Louis, Missouri). Mouse monoclonal COLI, monoclonal OPN and rabbit polyclonal RunX2, polyclonal OCN, goat anti-rabbit Alexa Fluor 488 (AF488) and goat antimouse Cy3 secondary antibodies were purchased from Santa Cruz Biotechnology Inc. (Paso Robles, California) and Sigma Aldrich. Mouse monoclonal COLI, OCN and OPN and polyclonal bone sialoprotein (BSP) antibodies, DRAQ5, goat anti-mouse Alexa Fluor 488 (AF488) were procured from Abcam (Cambridge, United Kingdom). RT-PCR reagents were purchased from Thermo Scientific (Waltham, Massachusetts). Rat BMP-2 and BMP-7 Enzyme-linked immunoabsorbance assay (ELISA) kits were purchased from Abnova Inc. (Taipei City, Taiwan and Qayee-Bio, Shanghai, China) respectively. All basic reagents (such as sodium chloride) were of high purity and purchased from recognised suppliers.

Clinical observations using HA-CS and HA-CS-G: uncontained bone defect after tumour resection. A 35-year-old man underwent wide resection of a low-grade periosteal chondrosarcoma (Fig. 1) from his right posterior distal femur in October 2013. Joint-preserving multiplanar femoral osteotomies and placement of a lateral locked plate (LISS, Synthes, West Chester, Pennsylvania), to stabilise the anterior cortical remnant, were performed with the help of intra-operative 3D CT-based computer navigation (O-arm and Medtronic Stealth, Medtronic, Dublin, Ireland). This was followed by bone defect reconstruction with $20 \mathrm{ml}$ of demineralised bone matrix (20 ml, DBX, Synthes), fashioned into a shallow wall around the entire circumference of the resection area, before implantation of $30 \mathrm{ml} \mathrm{HA}-\mathrm{CS}-\mathrm{G}$ and $36 \mathrm{ml}$ of HA-CS into the remaining bone defect. The hardened bone substitute was covered with collagen sponges (Spongostan, Ferrosan, Søborg, Denmark) and residual overlying musculature, before tight closure in layers over two deep drains.

Chronic osteomyelitis. A 65-year-old woman, with well controlled epilepsy, asthma and eczema, who was a smoker, presented with a 44-year history of recurrent osteomyelitis after a closed distal tibial fracture, initially treated with internal fixation. The fracture healed but with a persistent sinus and a constant purulent discharge for more than 20 years (Fig. 2a). Two previous attempts to excise and eradicate the infection had been unsuccessful. MRI revealed a Cierny-Mader type 3B osteomyelitis, ${ }^{26}$ 


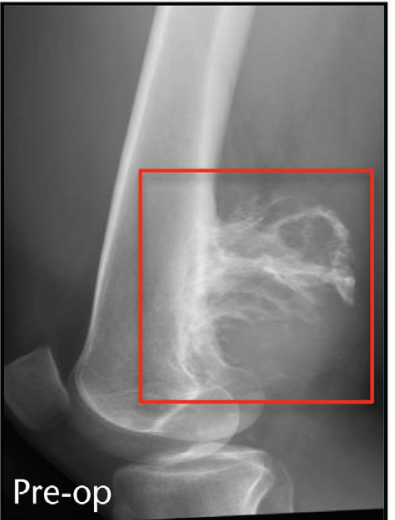

Fig. 1 a

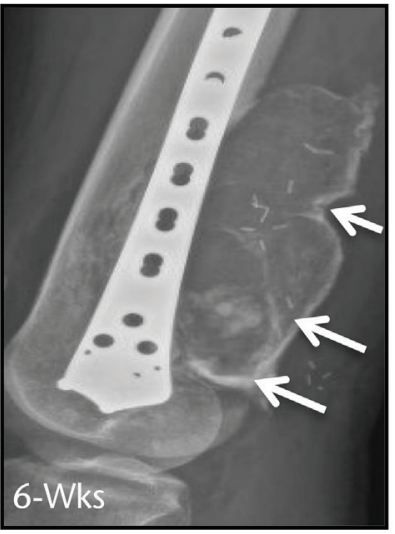

Fig. 1e

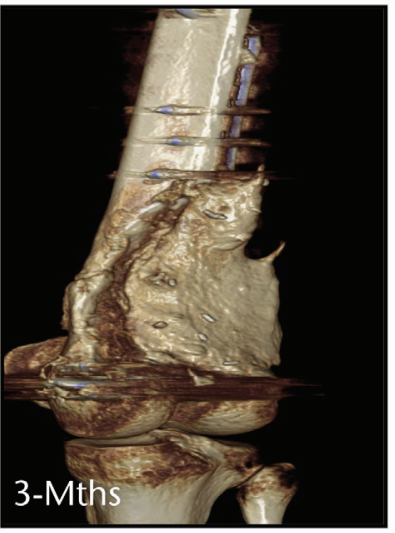

Fig. $1 \mathrm{i}$

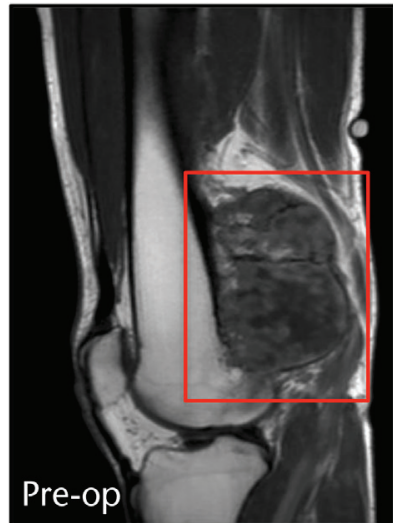

Fig. $1 \mathrm{~b}$

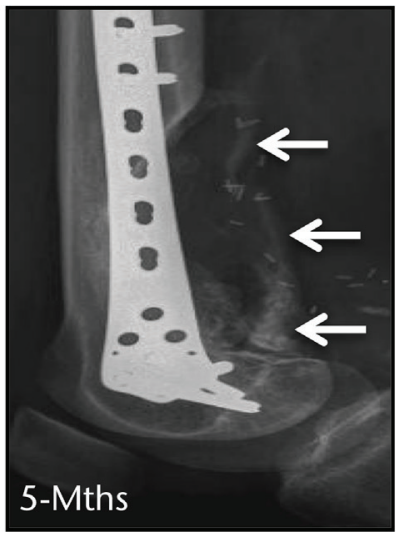

Fig. $1 f$

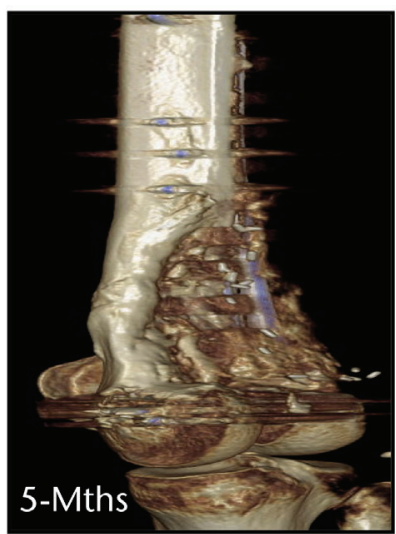

Fig. $1 \mathrm{j}$

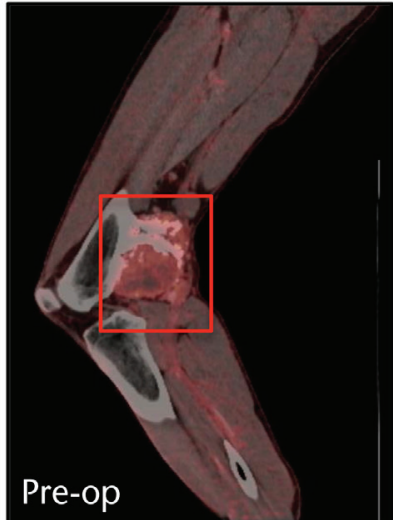

Fig. 1c

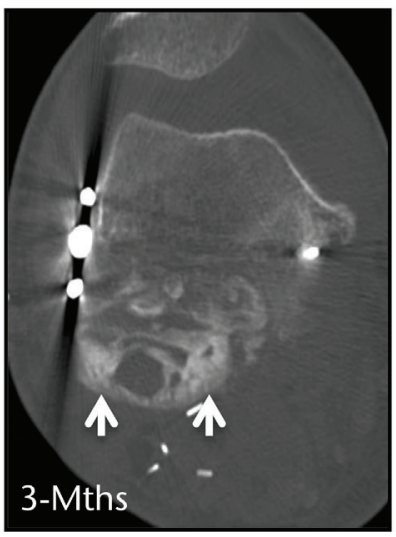

Fig. $1 \mathrm{~g}$

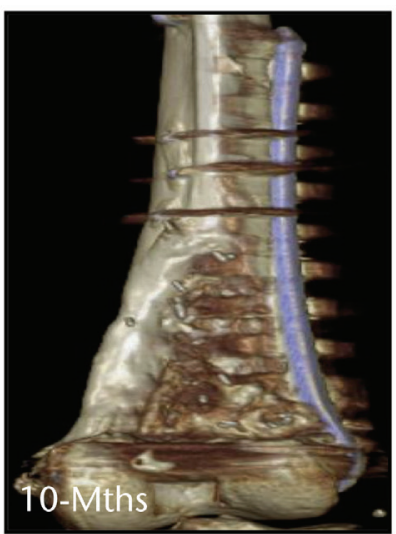

Fig. $1 \mathrm{k}$

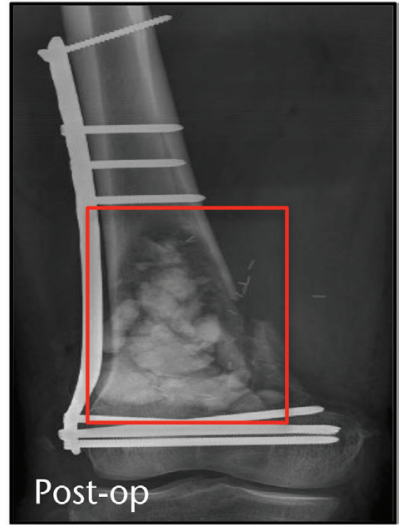

Fig. 1d

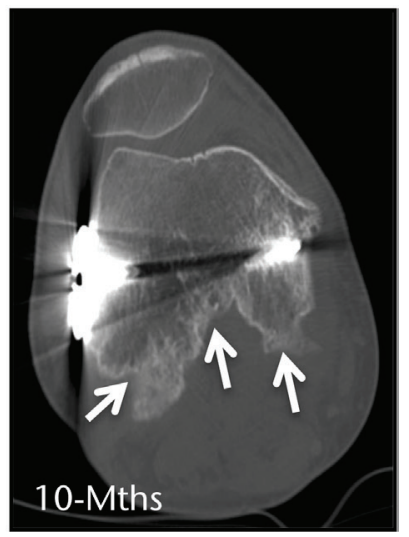

Fig. $1 \mathrm{~h}$

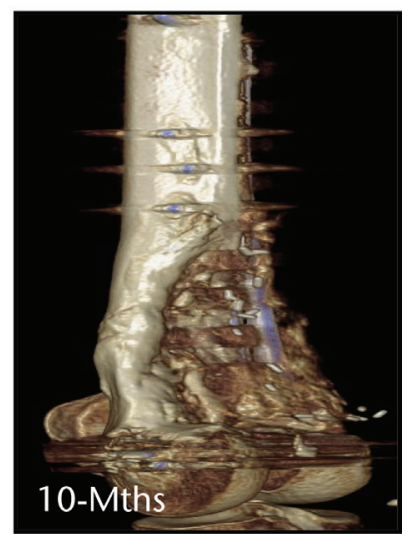

Fig. 11

Time course observations of bone defect from a wide periosteal chondrosarcoma resection, treated with hydroxyapatite-calcium sulphate (HA-CS) and HA-CSgentamicin (G) biomaterial. Panels (a), (b) and (c) represent pre-operative radiograph, MRI and PET-CT images of the tumour (red box), while panel (d) shows the bone defect filled with the biomaterial (red box) post-operatively. Arrows in the radiographs in panel (e) indicate bone formation in areas of direct muscle contact with HA-CS and HA-CS-G six weeks post-operatively, while arrows in panel (f) indicate reduced opacity of the regenerate at five months. Arrows in CT images in panels (g) and (h), respectively, indicate bone formation in the treated area posterior to the distal supracondylar region at three months postoperatively, progressively remodeling at ten months. Panels (i) through to (I) represent 3D reconstructions of CT images at three (i), five (j) and ten months (k), (I) showing progressive bone remodeling around the defect.

involving the medullary bone and adjacent cortex (Fig. 2b). In May 2013, the infected bone and the soft tissue were radically excised and $10 \mathrm{ml}$ of HA-CS-G was implanted in the resected area (Fig. 2c). Soft-tissue reconstruction was carried out using a free gracilis muscle flap and skin graft.
Material preparation for in vitro experiments. The two types of bone substitutes, HA-CS and HA-CS-G, were mixed as per supplier's guidelines (Bone Support $A B$ ) to form a homogenous paste. The paste was poured into a disc-shaped mould, $8 \mathrm{~mm}$ in diameter and $2 \mathrm{~mm}$ in height, and allowed to set for 30 minutes. Thereafter, 


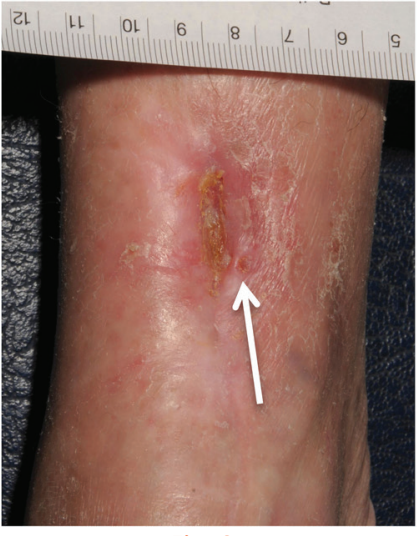

Fig. $2 a$

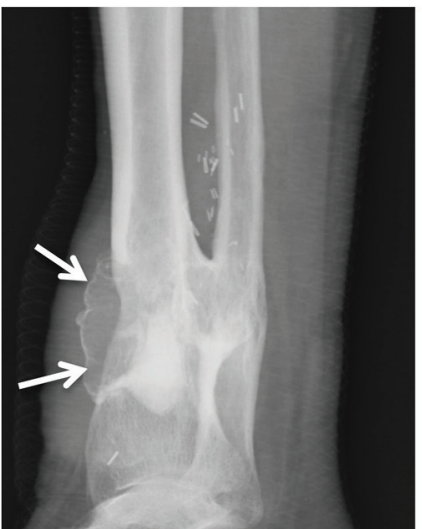

Fig. $2 d$

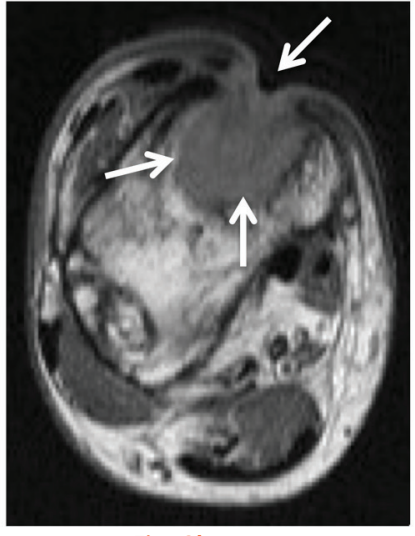

Fig. 2b

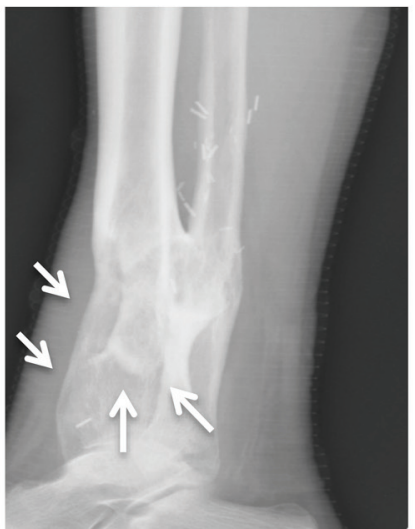

Fig. 2e

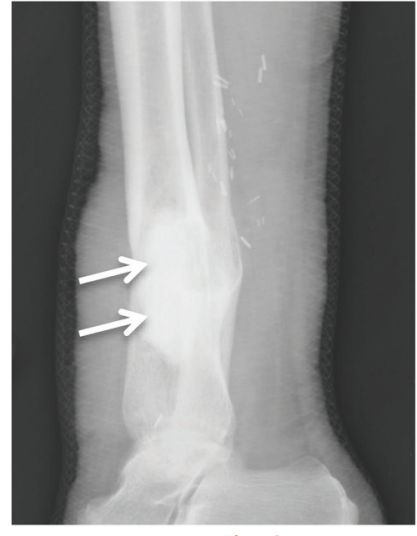

Fig. 2c

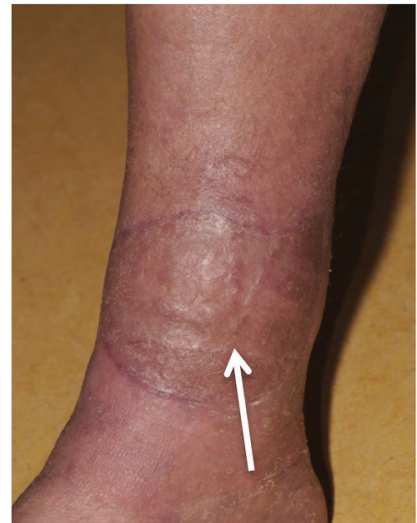

Fig. $2 f$

Time course observations from resected osteomyelitis treated with hydroxyapatite-calcium sulphate-gentamicin (HA-CS-G) biomaterial. Panel (a) is a digital image of the chronic osteomyelitis area of the tibia with visible wound as indicated by the arrow. Panel (b) represents a pre-operative MRI image used for diagnosis of osteomyelitis with white arrows emphasising the infected area. Radiograph in panel (c) represents the infected area filled with 10 ml of HA-CS-G post-operatively as indicated by white arrows while arrows in panel (d) indicate mineralisation in the overlaying muscle flap, four weeks post-operatively. Panel (e) represents a radiograph taken seven months post-operatively with arrows representing the resorbed bone previously observed at four weeks, while panel (f) represents a digital image of the healed wound seven months post-operatively.

discs with the set material were taken out of the mould and were used for further analysis.

Cell culture. Mouse myoblast $\mathrm{C} 2 \mathrm{C} 12$ cells were cultured in DMEM supplemented with $10 \%$ FBS and antibiotics. Cells were kept in an incubator with $95 \%$ air and $5 \% \mathrm{CO}_{2}$. For the proliferation and functionality experiments, $1 \times$ $10^{5}$ cells were seeded onto the HA-CS and HA-CS-G discs, while for immunofluorescence staining and reverse transcription polymerase chain reaction (RT - PCR), $1 \times 10^{6}$ cells were seeded onto the HA-CS discs only. The rat skeletal muscle myoblast cell line L6 was cultured in DMEM with a high glucose $(4500 \mathrm{mg} / \mathrm{L})$ mixture supplemented with $10 \%$ by volume (v/v) FBS and $1 \% \mathrm{v} / \mathrm{v}$ antibiotic cocktail consisting of penicillin-streptomycin. Cells were passaged at $80 \%$ confluence and were used at second passage after revival. Cell viability before experiments was evaluated using the trypan blue exclusion method, where dead cells stain blue and are excluded from the count.

In order to mimic in vivo conditions that lead to bone formation in the muscle tissue, we harvested osteoblast cell-derived proteins from an expanded cell culture of ROS $17 / 2.8$ osteoblastic cells. Cells were allowed to proliferate in culture flasks supplemented with complete medium and $5 \% \mathrm{v} / \mathrm{v}$ serum for a period of three days. The secreted bone active proteins in the medium were collected while the cells were passaged again to repeat the procedure.

To ensure differentiation of muscle cells into osteoblastlike cells, we used the rat muscle cell line L6. The cells were allowed to grow to $80 \%$ confluence, after which they were either supplied with low serum ( $5 \% \mathrm{v} / \mathrm{v})$ complete medium or a mixture of complete medium (low serum) and harvested osteoblast cell medium in an equal ratio by volume. The cells were allowed to grow for a period of ten or 12 days and were analysed using different techniques outlined below to confirm a shift in their phenotype.

Microscopic analysis. Surface morphology of the materials and adherence of the C2C12 cells on the surface of HA-CS and HA-CS-G discs were analysed using scanning electron microscopy. Materials were dehydrated 
by gradient ethanol treatment, vacuum dried overnight and gold coated (Sputter Coater, Cressington Watford, United Kingdom). For analysing the cell adherence on the biomaterial surface, cells were seeded on both the materials i.e. HA-CS and HA-CS-G. The cells were allowed to grow for three days. Thereafter, glutaraldehyde (2.5\%) was used to fix all of the cells on the surface. Steps following fixation were the same as were used for sample preparation for surface morphology analysis as described above with an exception of gold coating. Furthermore, attachment of cells on the HA-CS and HA-CS-G discs was analysed using 4',6-diamidino-2-phenylindole (DAPI) staining. 27

Cell proliferation assay. Cell proliferation on both the materials was evaluated using MTT assay at regular time intervals. Briefly, the DMEM media in the wells was removed, and cell-seeded biomaterial discs were washed using phosphate buffer saline (PBS). Thereafter, DMEM media, without FBS, containing MTT $(0.5 \mathrm{mg} / \mathrm{ml})$ was added in the wells with an incubation time of five hours. Furthermore, this solution was removed and dimethyl sulfoxide (DMSO) was added. The samples were incubated for 20 minutes at $37^{\circ} \mathrm{C}$. The coloured solution formed was collected and absorbance was measured spectrophotometrically at $570 \mathrm{~nm} .^{28}$

Cell proliferation analysis in the cell medium experiments using L 6 cells was done in a similar manner, and a cell density of $5 \times 10^{4}$ cells/well was used. The proliferation of myotubes was analysed by microscopy, and multinucleated and elongated cells were considered to be myotubes.

Alkaline phosphatase assay. Sigmafast para-Nitrophenylphosphate (pNPP) (Sigma Aldrich) tablets were used to prepare pNPP substrate solution, using the protocol provided by the manufacturer. The media were removed from the wells, and samples were washed using PBS buffer. The samples were then incubated with pNPP substrate solution for two hours in the $\mathrm{CO}_{2}$ incubator at $37^{\circ} \mathrm{C}$, and absorbance was measured at $405 \mathrm{~nm} .^{28}$

Immunofluorescence staining for osteogenic markers. The osteoinductive potential of the HA-CS biomaterial was observed using immunofluorescence staining. The seeded cells were cultured in non-osteogenic medium for different time points and stained to detect the presence of different markers including runt-related transcription factor-2 (RUNX2), osteopontin (OPN), osteocalcin (OCN) and collagen type I ( $\mathrm{Col} \mathrm{I}$ ) over the period of 21 days. To confirm the differentiation of L6 muscle cells into osteoblast-like cells, we immunostained cells in both groups for various osteoblastic markers Col I, OCN, OPN and bone sialoprotein (BSP). Cells were allowed to grow in culture flasks for a period of ten days in a complete medium with osteoblast-harvested bone active proteins or low serum. The cells were trypsinised and seeded on four-well chamber slides and allowed to proliferate with the same medium for a further 48 hours. On the day of staining (day 12), cells were fixed using $4 \%$ formaldehyde for ten minutes followed by membrane permeabilisation using $0.1 \% \mathrm{v} / \mathrm{v}$ triton $\mathrm{x}-100$ for five minutes. Cells were immediately blocked using $5 \%$ goat serum for one hour and incubated with respective primary antibodies for two hours at room temperature. Slides were washed five times with phosphate buffer saline with tween-20 (PBST), followed by incubation in secondary antibody (labelled AF488) for one hour followed by five more washes. The slides were counterstained using DRAQ5 for five minutes and washed twice for five minutes each. After drying, the slides were cleared, mounted and allowed to dry overnight before analysis. The cells were analysed on a Zeiss confocal microscope (Carl Zeiss AG, Oberkochen, Germany) at different magnifications.

RNA extraction and RT-PCR. The discs of HA-CS were seeded with $\mathrm{C} 2 \mathrm{C} 12$ cells at a concentration of $1 \times 10^{6}$ cells/disc. The RNA was extracted using TRIzol Reagent, after in vitro culturing of cell-seeded discs for the time period of seven days and 21 days. Cell-seeded discs were transferred from multiwell plates to microtubes after adding $1 \mathrm{ml}$ of TRIzol Reagent. Thereafter, RNA was isolated by following the protocol supplied by the manufacturer. Complimentary DNA (CDNA) was synthesised by incubating isolated RNA $(20 \mu \mathrm{l})$ with $1 \mu \mathrm{l}$ of oligo(dT) at $75^{\circ} \mathrm{C}$ for five minutes, followed by incubation in ice for five minutes. The cDNA mix, $4 \mu$ l of buff RT, $1 \mu$ l of RTase, 0.5 $\mu$ l of RI (Rnase inhibitor) and $2 \mu$ of dNTP mix were then added. RT-PCR was conducted to evaluate the expression of various genes of the osteogenic lineage such as RUNX2, Col I, BSP and OCN. The primer sequences of the genes are obtained from previous reports. ${ }^{29-31}$ As an endogenous control, expression of glyceraldehyde 3-phosphate dehydrogenase (GAPDH) was determined. A consecutive thermal cycle was used for DNA amplification. Products of RT-PCR were resolved on a $2.0 \%$ agarose gel stained using ethidium bromide.

Morphological changes using light microscopy and haematoxylin and eosin staining. The differentiation of muscle cells with the addition of osteoblast-harvested bone active proteins was analysed over a period of several days. Morphological analysis was performed using both light microscopy and Haemotoxylin and Eosin $(\mathrm{H}$ and E) staining. Culture flasks were directly monitored using a light microscope at different magnifications. In order to perform $\mathrm{H}$ and $\mathrm{E}$ staining, cells were grown in four-well chamber slides and were fixed with $4 \%(w / v)$ formaldehyde for ten minutes. Cells were hydrated with reducing ethanol gradient and stained with hematoxylin for five minutes. Excessive stain was washed off using running water, followed by counterstaining with eosin for two minutes. The slides were cleaned in xylene for five minutes, then mounted and dried overnight before imaging. 


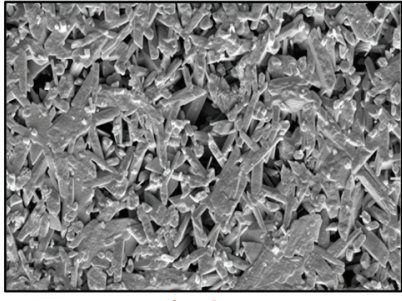

Fig. $3 a$

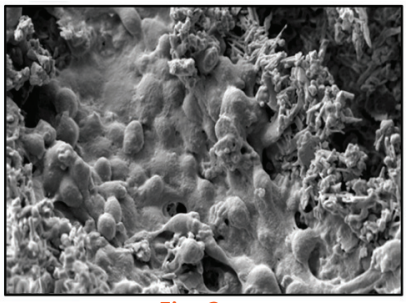

Fig. 3c

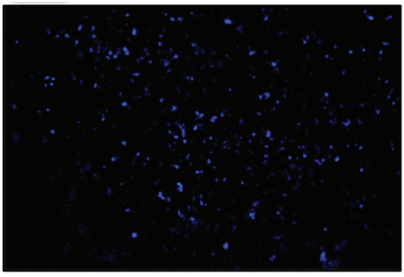

Fig. 3e

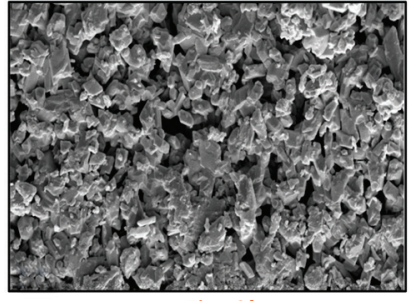

Fig. 3b

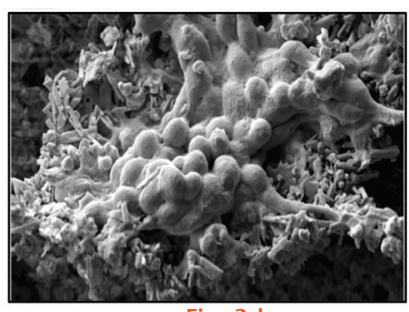

Fig. 3d

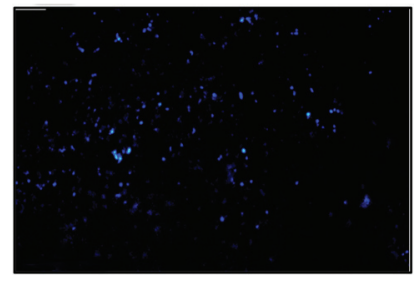

Fig. $3 f$
Scanning electron microscopy (SEM) and cell material interactions. SEM images in panel (a) and (b) represent hydroxyapatite-calcium sulphate (HACS) and HA-CS-gentamicin (G), respectively, at high magnification (3000x). SEM and microscopic analysis of $\mathrm{C} 2 \mathrm{C} 12$ muscle myoblasts proliferating on HA-CS (c, e) and HA-CS-G (d, f) three days post-seeding.

Osteoblast secretome composition. In an attempt to detect various pro-osteoblastic proteins in the ROS $17 / 2.8$ cell factory, we dialysed the harvested cell media against ultrapure water for a period of 48 hours using an $8 \mathrm{kDa}$ dialysis membrane. After dialysing, the proteins were concentrated using freeze-drying for a period of 48 hours. The dried protein fraction was later analysed using ELISA for the detection and measurement of two important bone active molecules BMP-2 and BMP-7.

Statistical analysis. Data from the MTT and alkaline phosphatase (ALP) assay were analysed using unpaired t-test. A $p$ value of $<0.05$ was considered to be significant. Data from the MTT assay and myotube numbers were analysed using a non-parametric, multiple $t$-test, and $\mathrm{p}<0.05$ was considered statistically significant. Data are shown in triplicate with mean and standard deviation (SD).

\section{Results}

Clinical observations using HA-CS and HA-CS-G: uncontained bone defect after tumour resection. The tumour was resected and filled with both HA-CS and HA-CS-G (Figs 1 a to $1 \mathrm{~d}$ ). Post-operative recovery was protracted due to delayed wound healing in a small area in the popliteal fossa and transient peroneal nerve neuropraxia, which took six months to fully subside. Immediate postoperative radiographs demonstrated almost complete filling of the defect (Fig. 1d). A large radio-dense regenerate with a sclerotic rim and increasing lucency towards its centre had formed six weeks post-operatively (Fig. 1e). Gradual reduction in its overall size was observed at each subsequent follow-up radiograph, while the sclerotic rim intensified up to the three-month mark, before slowly regressing again over its central aspect (Fig. 1f). CT scans at three, five and ten months post-operatively showed increasing bone remodeling, most prominently in distal (Figs $1 \mathrm{~g}$ and $1 \mathrm{~h}$ ) and medial femur (Figs $1 \mathrm{i}$ to $1 \mathrm{I})$. Clinically, the patient had normal range of movement and was able to bear weight fully without pain 11 months post-operatively.

Chronic osteomyelitis. The patient with recurrent osteomyelitis was treated with the gentamicin-eluting bone substitute (HA-CS-G) (Figs 2a to 2c). After surgery, she recovered well with complete wound healing and rapid mobilisation. Bone cultures were positive for Enterobacter cloacae, sensitive to gentamicin. Intravenous ertapenem treatment was initiated for six weeks, followed by six weeks of oral trimethoprim. Post-operative radiographs (Fig. 2c) showed good initial filling of the bone cavity with HA-CS-G. At four weeks, opacity was observed in the muscle overlaying the tibia that appeared as a bone shell (Fig. 2d). The bone shell surrounding the muscle reduced in size by 13 weeks but became denser. The bone defect was fully remodeled and trabecular bone was observed in the tibial defect area as seen from the radiograph (Fig. 2e). The opacity in the muscle also disappeared after seven months (Fig. 2e). The wound healed well (Fig. 2f). At review, 13 months after surgery, the patient had recovered, had no leg pain and the wound had healed with no discharge.

Microscopic analysis. The surface morphology of HA-CS and HA-CS-G discs were analysed using scanning electron microscopy, and both materials showed microporous structure with the size of the pores at the material surface in the range of $1 \mu \mathrm{m}$ to $10 \mu \mathrm{m}$ (Figs $3 \mathrm{a}$ and $3 \mathrm{~b}$ ). Cells were present on the surface of the biomaterial discs after three days of seeding. The cells were attached and homogenously distributed on both discs of HA-CS and HA-CS-G (Figs $3 \mathrm{C}$ and $3 \mathrm{~d}$ ). This was further confirmed by staining of the cells with DAPI that revealed a similar type of distribution pattern where seeded cells had adhered to and were evenly distributed on the surface of material (Figs $3 e$ and 3f).

Cell proliferation. Cell proliferation on the HA-CS and HA-CS-G discs was analysed using MTT assay in order to assess the biocompatibility of the biomaterials and to evaluate whether the addition of gentamycin incurs toxicity in this model. Similar results were observed in both biomaterials with or without gentamicin (Fig. 4a). After the initial increase in the cell population until the seventh day, the cell proliferation was suppressed and a decrease in cell population was observed at the later time points. On the 


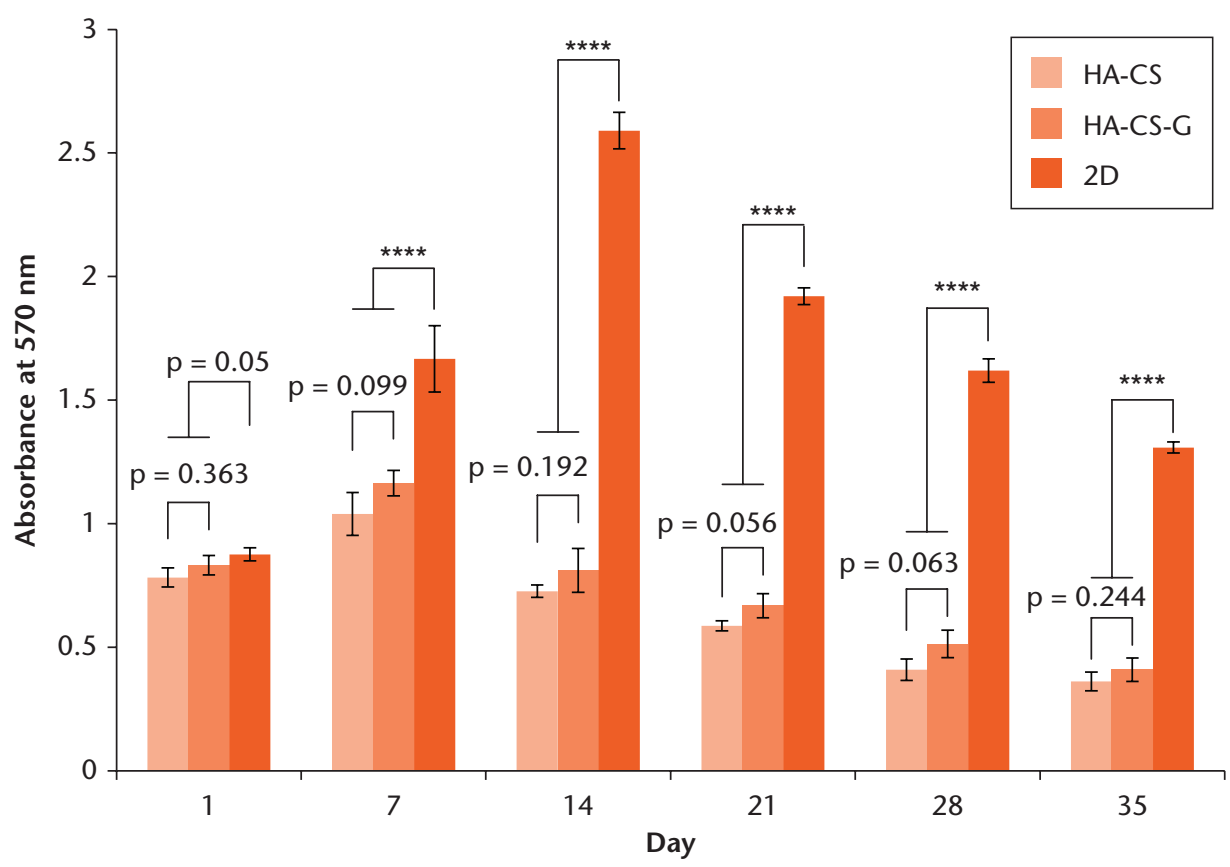

Fig. $4 a$

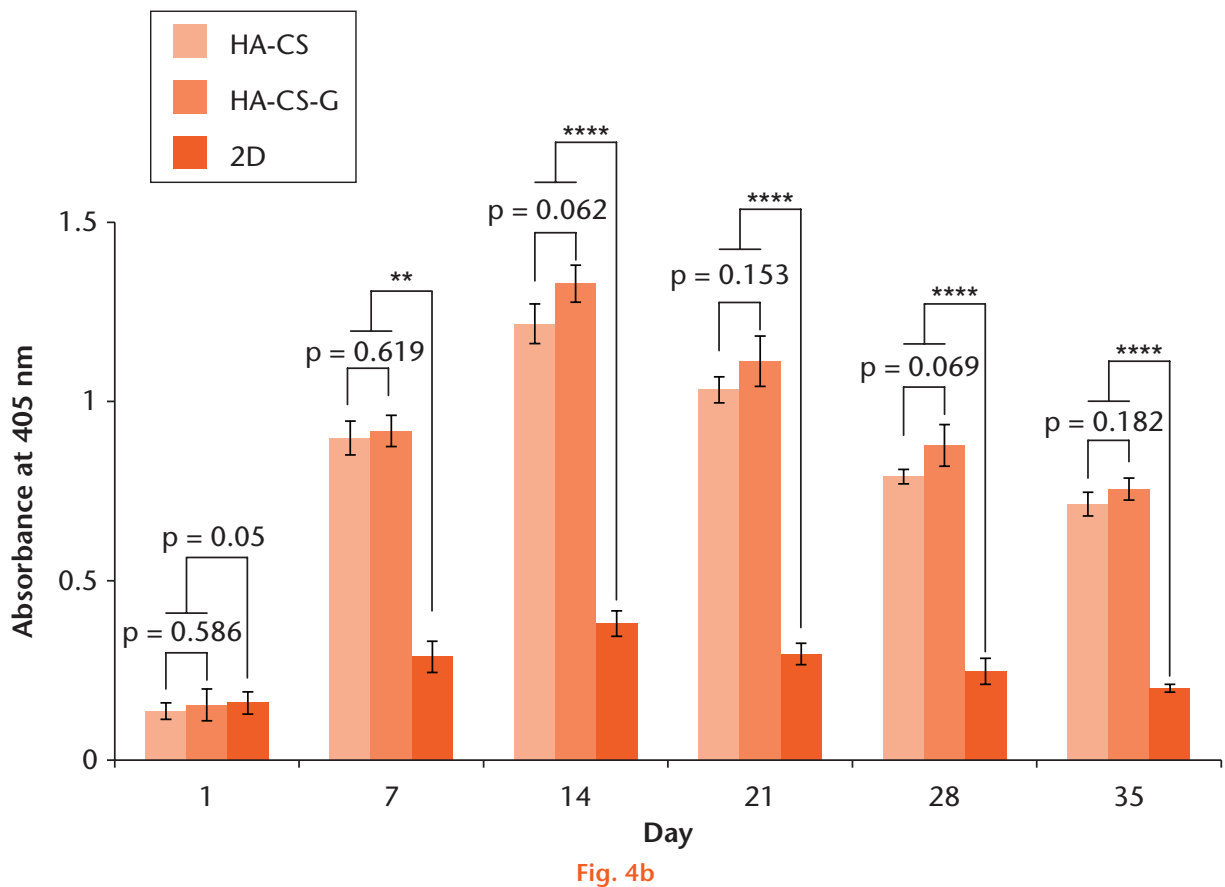

Cell culture study on hydroxyapatite-calcium sulphate (HA-CS) and HA-CS-gentamicin (G) biomaterials using C2C12 cells via 3-(4.5-dimethylthiazol-2-yl)2.5-diphenyltetrazolium bromide (MTT) and alkaline phosphatase (ALP) analysis. Panel (a) represents the proliferation pattern of C2C12 muscle myoblasts on HA-CS and HA-CS-G biomaterials over a period of five weeks post-seeding. Cellular proliferation was assessed via MTT assay with 2D polystyrene plates as a control for proliferation. Panel (b) represents alkaline phosphatase assay showing the level of ALP activity of C2C12 muscle myoblasts seeded on HA-CS and HA-CS-G compared with tissue culture plate over a period of 35 days. Unpaired $t$-test was used for statistical analysis and $p<0.05$ was considered significant. Data are represented as mean and standard deviation and the samples were taken in triplicate $(n=3)$.

other hand, in the case of two-dimensional polystyrene tissue culture plates, taken as a control, an increase in cell proliferation was observed until the fourteenth day, and thereafter proliferation declined. Cells seeded on both the materials showed a similar profile of cell proliferation. No statistically significant difference in cell proliferation was found ( $p>0.05)$. However, increased cell proliferation was found in the polystyrene tissue culture plate compared with HA-CS and HA-CS-G discs ( $p<0.0001)$.

Alkaline phosphate assay. The result of the ALP assay is shown in Figure 4b. The biomaterials (HA-CS and HA-CS-G) showed an increase in ALP by the 14th day of 


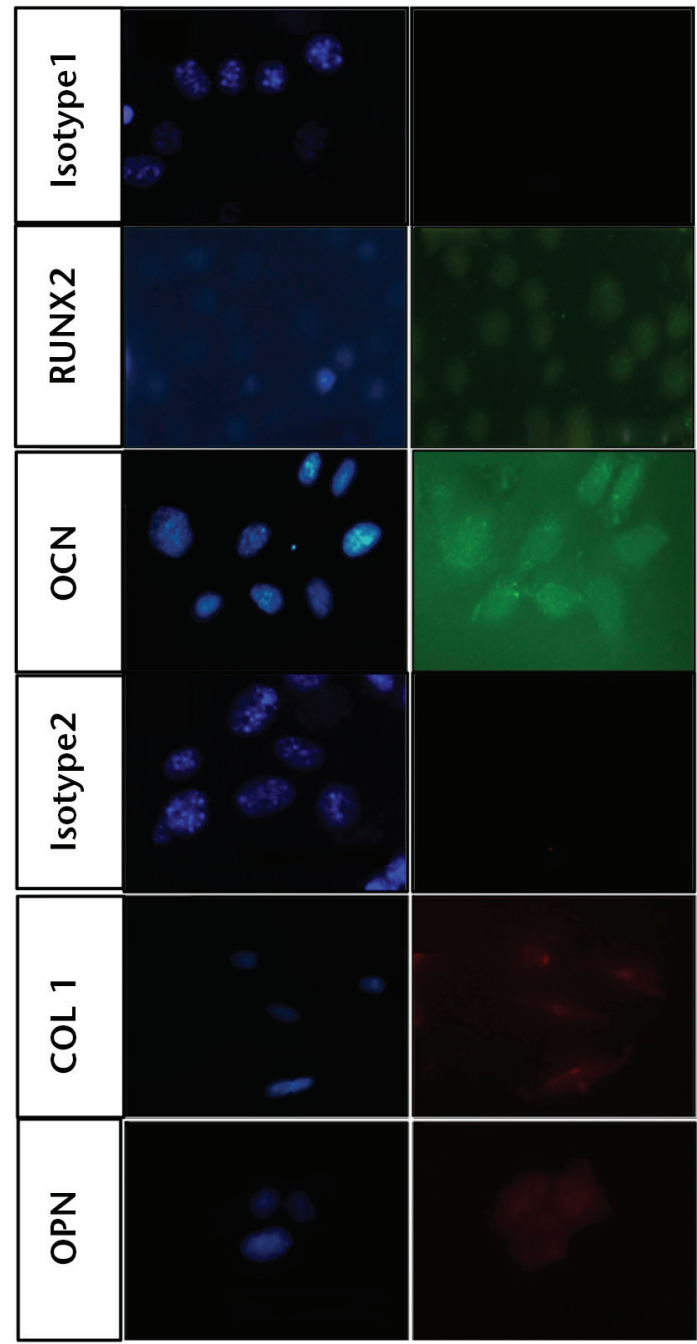

Fig. 5 a
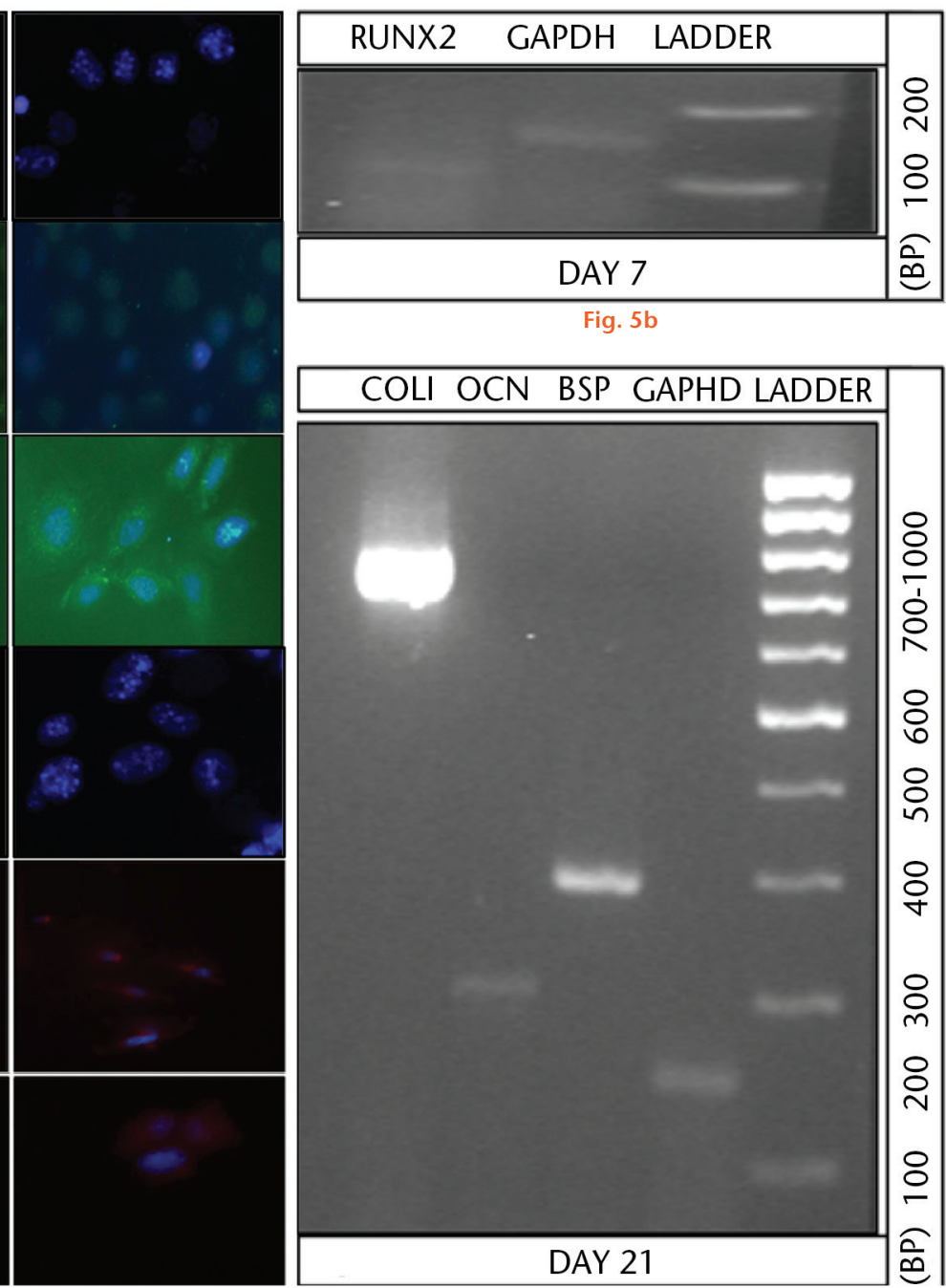

Fig. $5 c$

Immunocytochemical and real-time polymerase chain reaction analysis of C2C12 muscle myoblasts seeded on hydroxyapatite-calcium sulphate (HA-CS) biomaterial. C2C12 cells seeded on HA-CS were analysed using immunocytochemistry to visualise osteogenic differentiation. Cells were stained after a period of seven and 21 days post-seeding. The first row (a) shows the isotype control for goat anti-rabbit, Alexa Fluor 488 while the fourth row shows the isotype control for goat anti-mouse Cy3 secondary antibodies. Cells stained positive for osteogenic markers like RUNX2 (second row) at day seven, and polyclonal OCN (third row), Col I (fifth row), and monoclonal OPN (sixth row), after 21 days post-seeding. Images in the left hand panels (all rows) indicate nuclear staining using 4',6-diamidino-2-phenylindole staining while images in the middle panels (all rows) indicate antibody-based detection of respective target proteins while right hand panels (all rows) depict respective merged images (all $50 \mu \mathrm{m}$ ). Early onset of osteogenic differentiation was confirmed by the presence of the RUNX 2 gene in C2C12 cells seeded on HA-CS after seven days (b). Osteoblastic maturation (21 days post-seeding) of muscle cells was confirmed by the presence of osteoblastic gene coding for Col I (lane 1), OCN (lane 2), polyclonal bone sialoprotein (lane 3), and housekeeping gene glyceraldehyde 3-phosphate dehydrogenase (lane 4) with control ladder in (c), lane 5.

cell seeding. Thereafter, the values of ALP start decreasing with time. Within a time period of 14 days, cells seeded on both the HA-CS and HA-CS-G biomaterials showed an eightfold increase in ALP level when compared with polystyrene controls $(p<0.05)$. There was no statistically significant difference in the level of ALP between the two materials $(p>0.05)$. However, the level of ALP in the cells seeded on the polystyrene plate was less than that in the cells seeded on both biomaterials.

Immunofluorescence staining and RT-PCR. The presence of markers of mature osteoblasts was studied over the whole time period (Fig. 5). Immunofluorescence staining showed the presence of RUNX2 by the seventh day of cell seeding on the HA-CS disc. The presence of other markers of mature osteoblasts OCN, Col I, and OPN (all Fig. 5a) were detected by the 21 st day of cell seeding. Negative antibody controls are shown in Figure 5 (Isotype 1 and Isotype 2).

Osteopromotive potential of HA-CS was further confirmed by RT-PCR analysis of cells seeded on the material. Results showed the presence of RUNX2 by the seventh day (Fig. 5b) and the presence of other osteoblastic markers such as Col 1, BSP and OCN by the 21 st day of cell seeding (Fig. 5C).

The differentiation of muscle cells into bone cells after the addition of the cell culture-produced bone active proteins was confirmed using immunofluorescent staining 


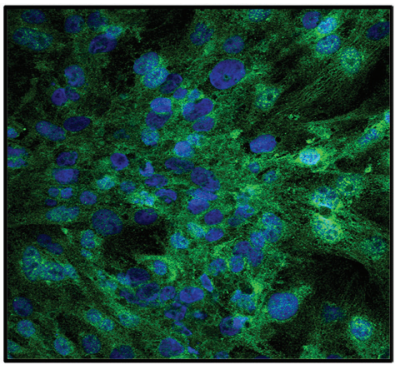

Fig. $6 a$

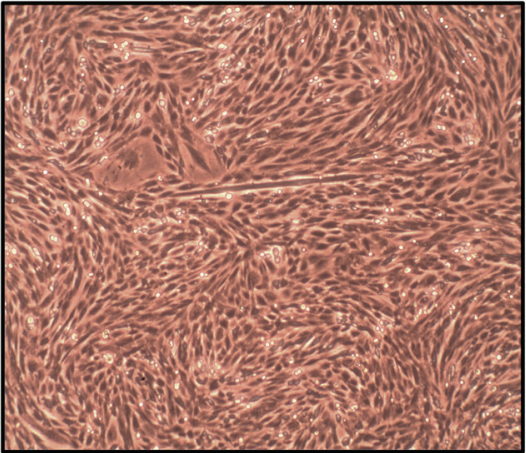

Fig. $6 \mathrm{e}$

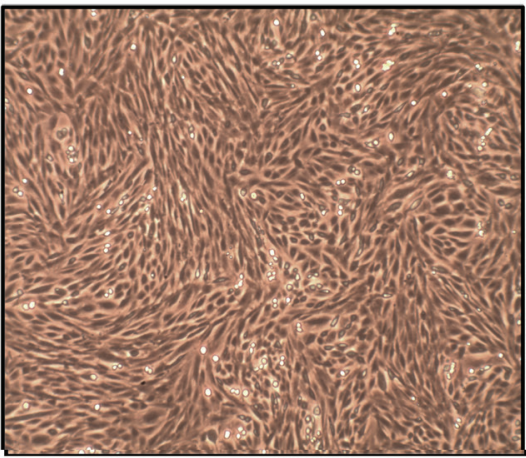

Fig. $6 \mathrm{~h}$

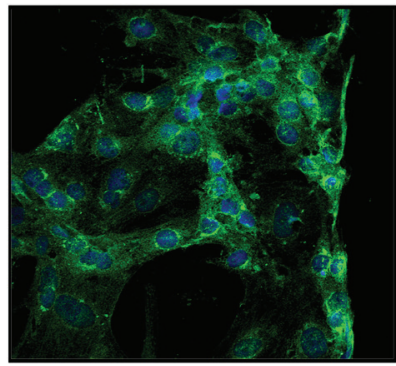

Fig. 6b

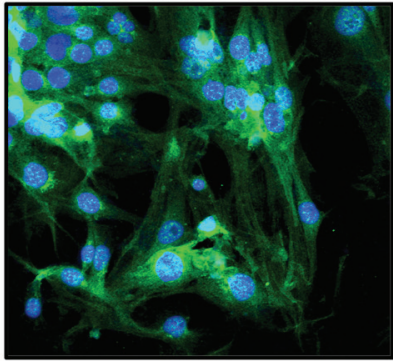

Fig. 6c

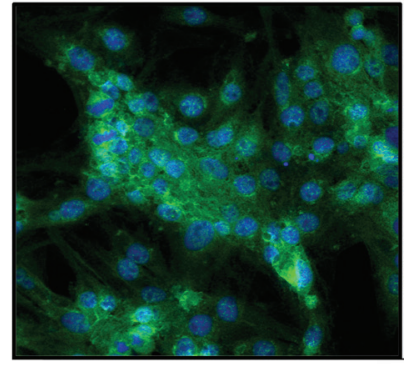

Fig. $6 d$

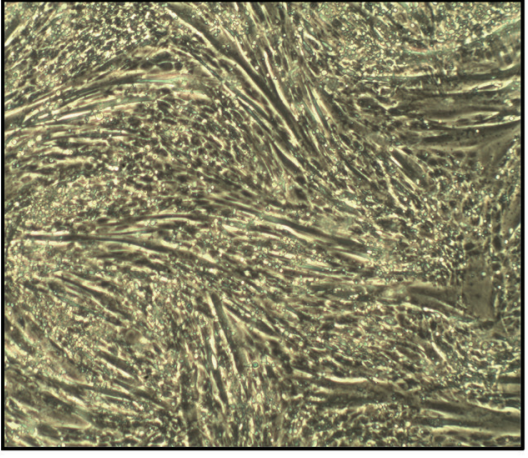

Fig. $6 \mathrm{f}$

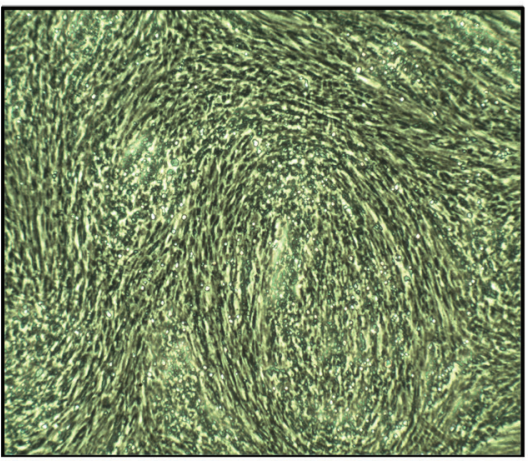

Fig. $6 \mathrm{i}$

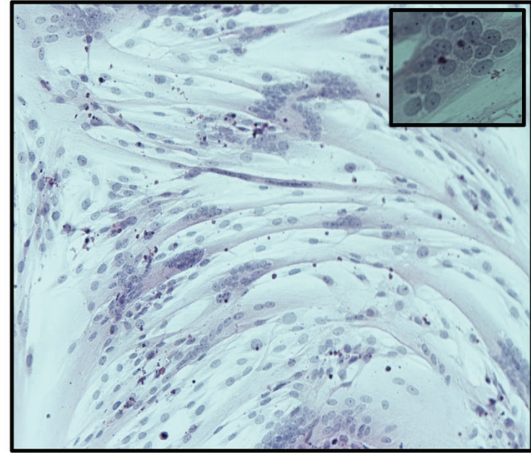

Fig. $6 \mathrm{~g}$

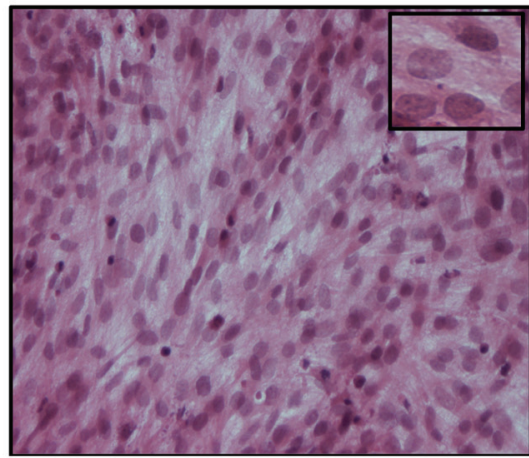

Fig. 6j

Effect of cell factory-derived bone active proteins on rat skeletal myoblast cell line L6. Immunocytochemical analysis of L6 muscle myoblasts treated with osteoblast-harvested bone active proteins using laser scanning confocal microscopy was carried out after a period of 12 days. Cells stained positive for most prominent osteoblastic markers Col I (a), polyclonal OCN (b), monoclonal OPN (c) and polyclonal bone sialoprotein (b). Nuclear staining (blue) was performed using DRAQ5. Scale bar indicates $10 \mu \mathrm{m}$. Images in panels $€$ and (f) (4× magnification) represent light microscopy images of L6 cells in the control group taken one day and ten days post-seeding, fusing together to form myotubes as seen in panel (f). Panel (g) represents Haemotoxylin and Eosin ( $\mathrm{H}$ and $\mathrm{E}$ )-stained myotubes ten days after seeding (10x magnification) while the inset picture ( $\mathrm{g}$ ) provides a high-magnification (40×) visualisation of an individual cell containing multiple nuclei, a behaviour typical of myotubes. Images in (h) and (i) (4x magnification) represent light microscopy images of L6 myoblasts treated with osteoblast-harvested bone active proteins after one and ten days, respectively. Panel (j) represents $\mathrm{H}$ and E-stained image of treated L6 cells. Inset in (j) represents uninucleated structure of myoblasts ten days following treatment with osteoblast proteins.

of cells in both groups for osteogenic markers such as Col I, OCN, OPN and BSP. Figure 6 (a to d) shows the immunopositive and transdifferentiated muscle cells transformed into osteoblast-like cells. The cells in the treated groups expressed osteogenic proteins such as $\mathrm{Col}$ I, OCN, OPN and BSP at day 12, while cells in the control group fused together to form myotubes and did not express osteogenic proteins.

Morphological changes using light microscopy and hematoxylin and eosin staining. A time course morphological difference was observed in cells treated with bone active proteins and the control groups. The cells in the control groups (Figs 6e to $6 \mathrm{~g}$ ) can be seen as elongated from as early as day one until the end of the experiment when compared with cells in the treated groups (Figs $6 \mathrm{~h}$ to $6 \mathrm{j}) . \mathrm{H}$ and $\mathrm{E}$ staining clearly illustrates the structural differences between the cells with and without treatment of growth factors (Figs $6 \mathrm{~g}$ and $6 \mathrm{j}$ ). In the case of controls, muscle cells differentiate into fused myotubes possessing a number of nuclei, while the cells in the group treated with growth factors remain uninucleated throughout the experiment. Moreover, the size of the cells is much smaller and possesses osteoblast-like morphology in the case of treated cells. 

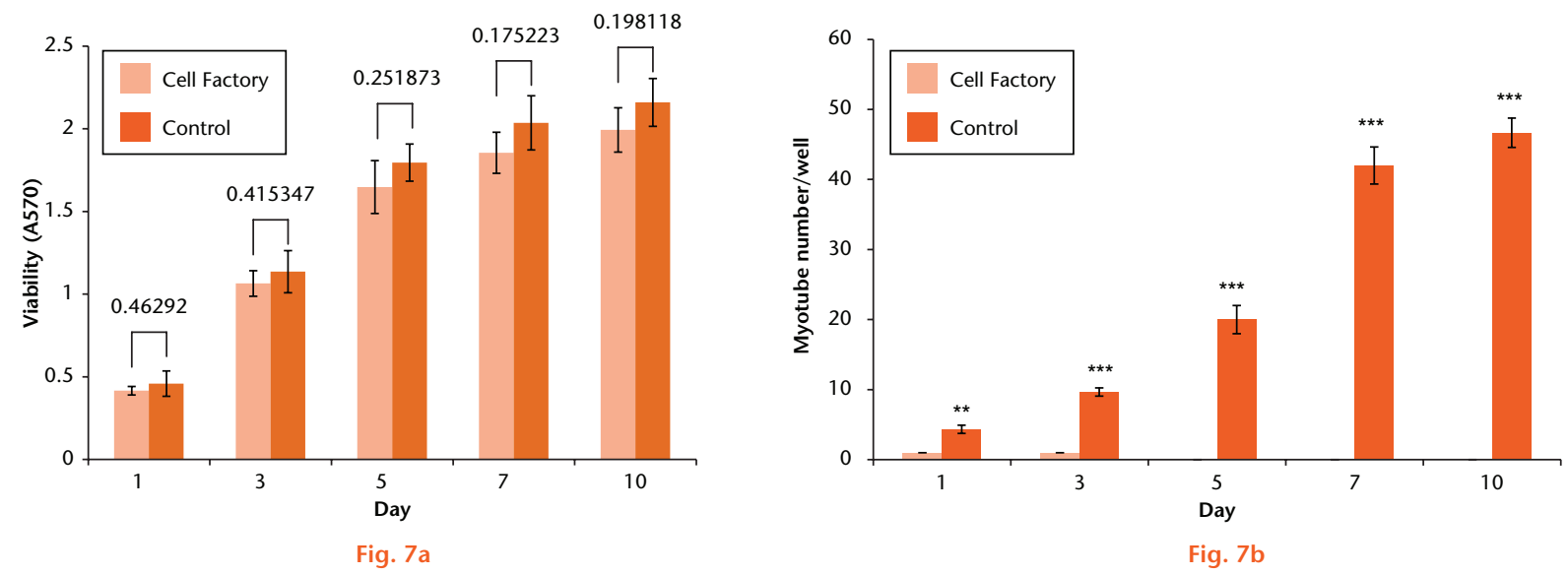

Cellular proliferation was assessed via 3-(4.5-dimethylthiazol-2-yl)-2.5-diphenyltetrazolium bromide assay (a). Myotube number/well in both groups was counted using light microscopy (b). Statistical analysis was performed using multiple $t$-tests; ** indicates $p<0.01$ and *** represents $p<0.001$. Data are represented as mean and standard deviation and the samples were taken in triplicate $(n=3)$.

Cell viability and myotube number. No significant difference in proliferation profile of cells was observed (Fig. 7a). On the contrary, cells in the control groups fused to form myotubes with multiple nuclei. We also analysed the number of myotubes that could be observed over a period of seven days, as represented in Figure 7b. The number of myotubes in the control group increased over time $(p<0.05)$, however, in the treated group very few myotubes were observed on day 1 and the number reached zero after day 3 , indicating complete suppression of myotube formation.

Osteoblast cell factory composition. We confirmed the presence of two of the most common osteoinductive proteins, BMP-2 and BMP-7, responsible for osteogenic differentiation of various mesenchymal cells into osteoblastic lineages. The detection of osteogenic proteins was performed using ELISA and the respective concentrations of BMP-2 and BMP-7 in the cell media were $8.4 \mathrm{ng} / \mathrm{mg}$ (SD 0.8) and $50.6 \mathrm{ng} / \mathrm{mg}$ (SD 2.2) of the harvested protein fraction.

\section{Discussion}

We have observed that muscle tissue in direct contact with HA-CS and HA-CS-G biomaterials had shown significant bone formation in a few clinical cases. To establish whether the biomaterial contributed to this phenomenon of bone formation, we have set up in vitro models to mimic the biological situations. We showed that an osteopromotive niche is provided by both HA-CS and HA-CS-G biomaterials, contributing to the differentiation of muscle cells towards an osteogenic lineage in vitro. Simultaneously, we harvested bone active proteins from multiplying bone cells in vitro and used them to differentiate muscle cells into bone-like cells. In clinical studies, it has been reported that when HA-CS or HA-CS-G is used to fill a bone defect, new bone is formed locally. ${ }^{32}$ However, new bone formation in the muscle in direct contact with the biomaterials was unforeseen and led us to explore the material behaviour with muscle cells. We also considered the possibility of growth factors and extra cellular matrix proteins released from the underlying bone cavity and acting synergistically with HA-CS and HA-CS-G. The perivascular niche in the muscle has stem cells and their recruitment to the underlying bone and the biomaterial is highly likely.

We have observed clinically extensive bone formation in the muscle surrounding HA-CS and HA-CS-G biomaterial as early as six weeks after surgery. Hydroxyapatitebased scaffolds have been known to induce bone formation in the muscle when used alone in larger animal models, thus corroborating well with our observations. ${ }^{33}$ However, the amount of time required for mineralisation in ectopic sites has always been longer than that which we have observed in our clinical case. In our opinion, this is an additional effect observed due to the presence of a ceramic matrix and bone active proteins leaking out of the bone cavity. Moreover, we have also observed resorption of the bone formed in the muscle five months post-operatively when compared with six weeks as observed from the images in Figures 1e and 1f. This might be because muscle is unloaded when compared with bone which leads to resorption. ${ }^{34}$ A similar phenomenon has also been observed in the osteomyelitis case (Fig. 2).

Upon physiochemically characterising the biomaterials using scanning electron microscopy (SEM), we verified the porous structure (Figs $3 a$ and $3 b$ ). It has already been reported that heterotopic bone formation was induced in the presence of micropores in ceramic materials. ${ }^{35,36}$ Porous HA-CS and HA-CS-G scaffolds provide sufficient surface area for cellular attachment and also an efficient environment for exchange of nutrients, gases and other signalling molecules. Cells were uniformly distributed across the surface of the scaffold as observed from SEM and DAPI analysis (Figs 3c to 3f). One noteworthy observation is the morphology of $\mathrm{C} 2 \mathrm{C} 12$ cells when 
seeded on HA-CS and HA-CS-G surfaces. We have, in our previous work, reported that when $\mathrm{C} 2 \mathrm{C} 12$ myoblasts are seeded on elastic biomaterials, they tend to form elongated myotubes, which in the current scenario is not seen. ${ }^{37}$ This led us to consider other phenotyping methods to understand changes in the skeletal muscle cell line $\mathrm{C} 2 \mathrm{C} 12$. The cellular proliferation was similar on both the scaffolds with and without gentamicin, indicating that the addition of gentamicin to the scaffold in our model does not cause toxicity in the cells (Fig. 4a). The scaffolds exhibited a gradual but suppressed proliferation of C2C12 muscle myoblasts when compared with tissue culture plates. However, this difference in the proliferation behaviour of cells on HA-CS and HA-CS-G discs and $2 \mathrm{D}$ tissue culture plate might be due to differentiation of myoblast $\mathrm{C} 2 \mathrm{C} 12$ cells to osteoblast lineage. It has been shown that the proliferation of cells is arrested during its differentiation. ${ }^{36,38,39}$ ALP is an important osteogenic marker, and an eightfold increase in the ALP activity (Fig. 4b) in the cells seeded on the discs of HA-CS and HA-CS-G clearly demonstrated the osteopromotive behaviour of the material, irrespective of whether gentamicin was added. This was the result of the $\mathrm{C} 2 \mathrm{C} 12$ cells that differentiated into osteoblasts, entering into maturation phase. ALP also acts as an osteogenic cell formation predictor. ${ }^{40-43}$ Cells seeded on a 2D polystyrene tissue culture plate showed lower values of ALP activity compared with that of the biomaterial discs (Fig. 4b). We observed the presence of prominent osteogenic markers such as RUNX2, Col 1, OCN and OPN in cells seeded on HA-CS discs. RUNX2 is reported as an osteoblast-specific transcription factor and a regulator of differentiation of osteoblasts. 21,44,45 The presence of other markers of mature osteoblasts such as OCN, Col I and OPN (Fig. 5a) was detected by the 21 st day of cell seeding. PCR results confirmed the gene expression of RUNX2, Col 1, OCN and BSP in the cells seeded on HA-CS, thus confirming the osteopromotive potential of HA-CS (Figs $5 b$ and $5 c$ ).

Another important aspect of our study was to address whether leaking bone active proteins from an open bone defect could induce bone formation both locally and in the muscle, as we observed in clinical cases. To address this question, the in vitro model closely simulates the in vivo situation by harvesting bone active proteins from an osteoblast cell line ROS 17/2.8 and observing their effect on muscle myoblast cell line L6. By microscopic analysis (phase contrast and $\mathrm{H}$ and $\mathrm{E}$ staining), we observed uninuclear and round morphology of cells over the course of 12 days in the case of the treated cells while the cells in the controls fused together to form myotubes with a significantly higher number than in the experimental group $(p<0.05)$, a behaviour typical of myoblasts (Fig. 7b). Immunostaining of cells in the treated group confirmed the phenotype shift with cells positive for important osteoblastic markers such as Col 1, OCN, OPN and BSP
(Figs $6 \mathrm{a}$ to $6 \mathrm{~d}$ ). The results are completely in accordance with earlier studies that establish the potential of BMP-2 and BMP-7 in differentiating skeletal muscle cells $\mathrm{C} 2 \mathrm{C} 12$ towards osteoblastic lineage. ${ }^{46,47}$ Both BMP-2 and BMP-7 can induce differentiation of skeletal muscle cells into bone in a dose- and time-dependent manner. We confirmed the presence of these two pro-osteogenic proteins in the harvested cell factory using ELISA.

It has previously been reported that inflammatory factors such as tumour necrosis factor- $\alpha$ (TNF- $\alpha$ ) secreted from a fracture site leads to differentiation of muscle cells. ${ }^{48}$ Also TNF- $\alpha$ obtained from culturing fractured bone in vitro can lead to osteogenic differentiation of muscle cells. However, in our clinical observation, ectopic bone formation was uncommon in patients with regular surgical intervention and was specifically seen when the biomaterial was used. In this study we focused more on material properties and the role of leaking bone active proteins rather than looking at inflammatory factors and cytokines. Thus, we have demonstrated a possible mechanism for bone formation in the muscle synergistically mediated by bone active proteins leaking from a bone defect and enhanced by HA-CS and HA-CS-G biomaterials.

In conclusion, in vitro studies performed with HA-CS and HA-CS-G biomaterials and muscle cell line C2C12 clearly show the osteopromotive effect of the ceramic material. Strong resemblance to native bone (due to the hydroxyapatite mineral phase) and microporosity and surface topography leads to differentiation of muscle myoblast cells into osteogenic cells when in contact with the biomaterial. We have also confirmed that a cocktail of growth factors containing BMP-2, BMP-7 and other bone active proteins, derived from osteoblast cells, can be harvested and used in a facile manner. These harvested growth factors are also able to induce the differentiation of muscle cells into bone cells. The clinical observations suggest that HA-CS and HA-CS-G biomaterials can induce bone formation in an overlaying muscle due to the osteopromotive properties of the material. Bone active proteins leaking from a bone defect also have the potential for osteogenic differentiation. The biomaterial and the leaking growth factors can lead to recruitment and differentiation of osteoprogenitor cells from the perivascular muscular niche to the material.

\section{References}

1. Habibovic P, de Groot K. Osteoinductive biomaterials-properties and relevance in bone repair. J Tissue Eng Regen Med 2007;1:25-32.

2. Coombes AG, Meikle MC. Resorbable synthetic polymers as replacements for bone graft. Clin Mater 1994;17:35-67.

3. Cornell CN, Lane JM. Current understanding of osteoconduction in bone regeneration. Clin Orthop Relat Res 1998;355(Suppl):S267-S273.

4. Damien CJ, Parsons JR. Bone graft and bone graft substitutes: a review of current technology and applications. J Appl Biomater 1991;2:187-208.

5. de Boer HH. The history of bone grafts. Clin Orthop Relat Res 1988;226:292-298.

6. Lane JM, Tomin E, Bostrom MP. Biosynthetic bone grafting. Clin Orthop Relat Res 1999;367(Suppl):S107-S117 
7. Urist MR. Bone: formation by autoinduction. Science 1965:150:893-899.

8. Yaszemski MJ, Payne RG, Hayes WC, et al. Evolution of bone transplantation: molecular, cellular and tissue strategies to engineer human bone. Biomaterials 1996;17:175-185.

9. Laurie SW, Kaban LB, Mulliken JB, et al. Donor-site morbidity after harvesting rib and iliac bone. Plast Reconstr Surg 1984;73:933-938.

10. LeGeros RZ. Calcium phosphate-based osteoinductive materials. Chem Rev 2008;108:4742-4753

11. Leung HB, Fok MW, Chow LC, Yen CH. Cost comparison of femoral head banking versus bone substitutes. J Orthop Surg (Hong Kong) 2010;18:50-54.

12. Yuan $\mathbf{H}$, Fernandes $\mathbf{H}$, Habibovic $\mathbf{P}$, et al. Osteoinductive ceramics as a synthetic alternative to autologous bone grafting. Proc Natl Acad Sci U S A2010;107:13614-13619.

13. Hutmacher DW, Schantz JT, Lam CXF, et al. State of the art and future directions of scaffold-based bone engineering from a biomaterials perspective. J Tissue Eng Regen Med 2007;1:245-260.

14. Gupta A, Bhat S, Chaudhari BP, et al. Cell factory-derived bioactive molecules with polymeric cryogel scaffold enhance the repair of subchondral cartilage defect in rabbits. J Tissue Eng Regen Med 2015 July 14. (Epub ahead of print)[[bibmisc]]

15. Fujibayashi S, Neo M, Kim H-M, et al. Osteoinduction of porous bioactive titanium metal. Biomaterials 2004;25:443-450.

16. Gosain AK, Riordan PA, Song L, et al. A 1-year study of osteoinduction in hydroxyapatite-derived biomaterials in an adult sheep model: part II. Bioengineering implants to optimize bone replacement in reconstruction of cranial defects. Plast Reconstr Surg 2004;114:1155-1163.

17. Li $\mathbf{X}$, van Blitterswijk CA, Feng $\mathbf{0}$, et al. The effect of calcium phosphate microstructure on bone-related cells in vitro. Biomaterials 2008;29:3306-3316.

18. Yuan H, De Bruijn JD, Li Y, et al. Bone formation induced by calcium phosphate ceramics in soft tissue of dogs: a comparative study between porous $\alpha$-TCP and $\beta$ TCP. J Mater Sci Mater Med 2001;12:7-13.

19. Yuan H, De Bruijn J, Zhang $X$, et al. Osteoinduction by porous alumina ceramic [abstract]. 16th European Conference on Biomaterials, 2001.[[bibmisc]]

20. Yuan H, Van Den Doel M, Li S, et al. A comparison of the osteoinductive potential of two calcium phosphate ceramics implanted intramuscularly in goats. J Mater Sci Mater Med 2002;13:1271-1275.

21. Tan Y, Wang G, Fan H, et al. Expression of core binding factor 1 and osteoblastic markers in $\mathrm{C} 2 \mathrm{C} 12$ cells induced by calcium phosphate ceramics in vitro. J Biomed Mater Res A 2007;82:152-159.

22. Wang EA, Rosen V, D'Alessandro JS, et al. Recombinant human bone morphogenetic protein induces bone formation. Proc Natl Acad Sci U S A 1990;87: 2220-2224.

23. Fillingham Y, Jacobs J. Bone grafts and their substitutes. Bone Joint J 2016;98B:6-9.

24. Asakura A, Komaki M, Rudnicki M. Muscle satellite cells are multipotential stem cells that exhibit myogenic, osteogenic, and adipogenic differentiation. Differentiation 2001;68:245-253.

25. Alfotawi R, Naudi K, Dalby MJ, et al. Assessment of cellular viability on calcium sulphate/hydroxyapatite injectable scaffolds. J Tissue Eng 2013;4:204.

26. Calhoun JH, Manring MM, Shirtliff M. Osteomyelitis of the long bones. Semin Plast Surg 2009;23:59-72

27. Gupta A, Bhat S, Jagdale PR, et al. Evaluation of three-dimensional chitosanagarose-gelatin cryogel scaffold for the repair of subchondral cartilage defects: an in vivo study in a rabbit model. Tissue Eng Part A 2014;20:3101-3111.

28. Mishra R, Kumar A. Osteocompatibility and osteoinductive potential of supermacroporous polyvinyl alcohol-TEOS-agarose-CaCl2 (PTAgC) biocomposite cryogels. J Mater Sci Mater Med 2014;25:1327-1337.

29. Ehara A, Ogata $\mathbf{K}$, Imazato $\mathbf{S}$, et al. Effects of $\alpha$-TCP and TetCP on MC3T3-E1 proliferation, differentiation and mineralization. Biomaterials 2003;24:831-836.

30. Hu S-Y, Tai C-C, Li Y-H, et al. Progranulin compensates for blocked IGF-1 signaling to promote myotube hypertrophy in $\mathrm{C} 2 \mathrm{C} 12$ myoblasts via the PI3K/Akt/mTOR pathway. FEBS Lett 2012;586:3485-3492.

31. Shen Y, Wang W, Li X, et al. Mitigative effect of erythromycin on PMMA challenged preosteoblastic MC3T3-E1 cells. Sci World J 2014;2014:107196

32. Abramo A, Geijer M, Kopylov P, et al. Osteotomy of distal radius fracture malunion using a fast remodeling bone substitute consisting of calcium sulphate and calcium phosphate. J Biomed Mater Res B Appl Biomater 2010;92:281-286.
33. Wang $\mathbf{H}$, Zhi W, Lu $\mathbf{X}$, et al. Comparative studies on ectopic bone formation in porous hydroxyapatite scaffolds with complementary pore structures. Acta Biomater 2013:9:8413-8421.

34. Aguirre JI, Plotkin LI, Stewart SA, et al. Osteocyte apoptosis is induced by weightlessness in mice and precedes osteoclast recruitment and bone loss. J Bone Miner Res 2006;21:605-615.

35. Yamasaki H, Sakai H. Osteogenic response to porous hydroxyapatite ceramics under the skin of dogs. Biomaterials 1992;13:308-312.

36. Zhang J, Barbieri D, ten Hoopen H, et al. Microporous calcium phosphate ceramics driving osteogenesis through surface architecture. J Biomed Mater Res A 2015;103:1188-1199.

37. Singh D, Nayak V, Kumar A. Proliferation of myoblast skeletal cells on threedimensional supermacroporous cryogels. Int J Biol Sci 2010;6:371-381.

38. Scott RE, Hoerl BJ, Wille JJ Jr, et al. Coupling of proadipocyte growth arrest and differentiation. II. A cell cycle model for the physiological control of cell proliferation. J Cell Biol 1982;94:400-405.

39. Xia K, Xue H, Dong D, et al. Identification of the proliferation/differentiation switch in the cellular network of multicellular organisms. PLoS Comput Biol 2006;2:e145.

40. Escudero N, Mandalunis P. Histochemical evaluation of alkaline phosphatase in subchondral bone of olpadronate-treated animals. Bone 2007;40:S7.

41. Gomez B Jr, Ardakani S, Ju J, et al. Monoclonal antibody assay for measuring bone-specific alkaline phosphatase activity in serum. Clin Chem 1995;41:1560-1566.

42. Havill LM, Rogers J, Cox LA, et al. QTL with pleiotropic effects on serum levels of bone-specific alkaline phosphatase and osteocalcin maps to the baboon ortholog of human chromosome 6p23-21.3. J Bone Miner Res 2006;21:1888-1896.

43. Van Hoof VO, De Broe ME. Interpretation and clinical significance of alkaline phosphatase isoenzyme patterns. Crit Rev Clin Lab Sci 1994;31:197-293.

44. Ducy P, Zhang R, Geoffroy V, et al. Osf2/Cbfa1: a transcriptional activator of osteoblast differentiation. Cell 1997;89:747-754.

45. Komori T, Kishimoto T. Cbfa1 in bone development. Curr Opin Genet Dev1998;8:494-499

46. Katagiri T, Yamaguchi A, Komaki M, et al. Bone morphogenetic protein-2 converts the differentiation pathway of $\mathrm{C} 2 \mathrm{C} 12$ myoblasts into the osteoblast lineage. J Cell Biol 1994;127:1755-1766

47. Yeh LCC, Tsai AD, Lee JC. Osteogenic protein-1 (OP-1, BMP-7) induces osteoblastic cell differentiation of the pluripotent mesenchymal cell line C2C12. J Cell Biochem 2002;87:292-304

48. Glass GE, Chan JK, Freidin A, et al. TNF- $\alpha$ promotes fracture repair by augmenting the recruitment and differentiation of muscle-derived stromal cells. Proc Natl Acad Sci U S A 2011;108:1585-1590.

Funding Statement

Funding has been received from BoneSupport which is related to this article.

M. McNally reports funding received from Heraeus and Novartis, none of which is related to this article.

- M. M. Peterson reports funding received from Pfizer Oncology and Zimmer Biomet which is not related to this article.

M. Tägil reports funding received from Surgacoll and Integra which is not related to this article.

$\mathrm{M}-\mathrm{H}$. Zheng reports funding received from Orthocell which is not related to this article.

A. Kumar has recevied funding from the Department of Biotechnology, Government of India

Author Contribution

D. B. Raina: Cell factory experiments, Manuscript writing.

A. Gupta: Experiments with osteoinductivity of HA-CS and HA-CS-G biomaterial, Manuscript preparation.

M. M. Petersen: Clinical case 1 preparation, Manuscript preparation.

W. Hettwer: Clinical case 1, Manuscript preparation.

M. McNally: Clinical Case 2, Manuscript preparation.

M. Tägil: Cell factory experiments, Study planning, Manuscript preparation.

M-H. Zheng: Study design, Planning and manuscript preparation.

A. Kumar: In vitro experiments, Study design, Manuscript preparation.

- L. Lidgren: Study design, Manuscript preparation.

D. B. Raina and A. Gupta have contributed equally to this work.

ICMJE conflict of interest

None declared

(c) 2016 Lidgren et al. This is an open-access article distributed under the terms of the Creative Commons Attributions licence (CC-BY-NC), which permits unrestricted use, distribution, and reproduction in any medium, but not for commercial gain, provided the original author and source are credited. 